\title{
RESSENYES
}

\section{Eduardo Pascual Ramos, El Decret de Nova Planta de Mallorca. Temps del Leviatan. Palma: Lleonard Muntaner, 2016, 96 pp.}

Este volumen proporciona un análisis del Decreto de Nueva Planta del 28 de noviembre de 1715 y su posterior normativa complementaria para el Reino de Mallorca. Su autor es Eduardo Pascual, especialista en Historia Moderna y doctor en Historia por la Universitat de les Illes Balears.

El primer capítulo trata de la doctrina asociada al decreto: la rebelión de los territorios de la Corona de Aragón en la Guerra de Sucesión española. Frente a la visión que cierra el conflicto en 1713 con el Tratado de Utrecht, Eduardo Pascual lo sitúa entre 1701 y 1715 y destaca que continuó en Cataluña hasta 1714 y en el Reino de Mallorca hasta 1715. Se plantea el debate historiográfico generado sobre si realmente se aplicó el derecho de conquista para la eliminación de las instituciones de la Corona de Aragón. El autor considera que se impone una monarquía absolutista que sitúa al «Estado» por encima del derecho y las instituciones. De esta última consideración surge el subtítulo de esta obra Temps del Leviatan, que alude a la superioridad del monarca que establecía Hobbes en su obra Leviatán. Pascual señala que este Decreto tuvo limitaciones, por las cuales «no va suposar un canvi substancial en els esquemes de comportament social ni del poder territorial» $\mathrm{y}$ que aunque pierde las características propias de un reino, como la potestad legislativa y la representación estamental en las instituciones, conserva el título de Reino de Mallorca de forma honorífica.

En los capítulos segundo y tercero se aborda la transición desde la caída de Mallorca (1715) hasta 1718 - fecha en la que ya quedarían totalmente perfiladas las nuevas instituciones-y la elaboración del Decreto de Nueva Planta relativo al antiguo reino. Se describen las tres capitulaciones - con el virrey, con la ciudad y Reino de Mallorca y con la Iglesia - establecidas en la toma de
Mallorca por el jefe militar felipista, el caballero d'Asfeld, que asume la Comandancia General del reino. D'Asfeld defenderá ante el rey muchos de los intereses de los mallorquines y será partidario de un decreto más benévolo que el que se aplicó finalmente. En esta etapa se tramita el Decreto de Nueva Planta para el Reino de Mallorca en medio de un gran desconocimiento de las instituciones y el sistema de gobierno mallorquín por parte del Consejo de Castilla. Esto dará lugar a un decreto ambiguo que generará numerosas consultas posteriores para su aplicación. Pascual explica que este texto contiene dieciocho artículos, en los que se generan confusiones en torno a cuestiones como la conservación o eliminación de algunos oficios e instituciones.

Los tres capítulos siguientes describen las instituciones en las diferentes islas del archipiélago. Así, en primer lugar se analiza la centralización generada por la pérdida de las instituciones regnícolas y la instauración del modelo castellano en la isla. La eliminación de la principal institución, el Gran $i$ General Consell, acabó con todo atisbo de poder legislativo del Reino. La principal representación del rey en la isla deja de ser el virrey, que es reemplazado por el comandante general, una figura con atribuciones más amplias que la anterior. Este presidía la Real Audiencia, máxima institución judicial en la isla y que no sufre grandes alteraciones. La Real Audiencia y el comandante general se reúnen en ocasiones para formar el Real Acuerdo, una novedad de este gobierno borbónico que servirá para tratar temas de gobierno. En cuanto a la Real Hacienda, se sustituye la Procuración Real por la Intendencia, la cual integra las rentas que antes pertenecían al Reino e impone en el territorio nuevos tributos, lo que aumenta la carga fiscal. El cambio más importante se da 
en el ámbito municipal al imponerse el modelo castellano de ayuntamientos. El Ayuntamiento de Palma se convertía en cabeza de corregimiento con un corregidor que simultaneó este cargo con el de intendente hasta 1772, un alcalde mayor que lo sustituyó en sus numerosas ausencias $\mathrm{y}$ veinte regidores procedentes de la aristocracia elegidos por el rey y con cargo vitalicio. Se estaba eliminando de esta forma la representatividad del resto de estamentos en las instituciones políticas e inutilizando el Sindicat de Fora, que había representado hasta el momento a las villas, a las cuales se otorgan dos representantes en el Ayuntamiento palmesano, pero básicamente para la recaudación de impuestos. En Alcudia también se da la elección de los regidores por el rey y de forma vitalicia y se le conserva su título de ciudad por los servicios prestados. En el resto de villas se constituyen también ayuntamientos con un batle a la cabeza y cuatro regidores, estructura que no supone grandes variaciones respecto a la anterior, aunque sí su sistema de elección, que tras eliminarse la insaculación pasan a designarse sus cargos por la Real Audiencia. Se elimina la ley de extranjería, lo que dará acceso a los oficios de la isla a todos los súbditos del rey.

A continuación, se explican las reformas llevadas a cabo por Carlos III en 1766 por las que introduce al síndico personero y a los diputados del común en los ayuntamientos, los cuales eran elegidos por votación de los contribuyentes a doble vuelta. También se aborda la reforma policial de 1768 , en la que se divide Palma en cuatro cuarteles, en cada uno de los cuales se instaura un alcalde de cuartel y seis alcaldes de barrio responsables de conservar el orden público.

El siguiente capítulo hace referencia a Ibiza y Formentera. En estas islas no se aplica la Nueva Planta como tal hasta el año 1724 debido a la imprecisión del Decreto. La máxima autoridad política, judicial y militar de este territorio era el gobernador. La Hacienda Real en estas islas era administrada por un delegado de la intendencia de Mallorca. Eduardo Pascual asegura que los cambios más importantes se produjeron en el ámbito municipal, ya que se eliminó la principal institución insular, el Consell General d'Eivissa, por lo que lo que en este se trataba debía pasar al
Ayuntamiento de Ibiza. Este ayuntamiento, a diferencia del de Palma, tendrá representados a los diferentes estamentos de la sociedad. Se intenta aplicar este sistema de ayuntamiento en el resto de las villas, pero fracasa. No será hasta finales del siglo xviII cuando Manuel Abad y Lasierra -al que se nombra obispo de Ibiza- y el asesor del gobernador Miquel Gaietà Soler lleven a cabo medidas ilustradas y la construcción de dieciocho parroquias en torno a las cuales se concentrará la dispersa población ibicenca y se formarán ayuntamientos.

El último capítulo está dedicado a Menorca. Se explica la continuidad del sistema de gobierno anterior al Decreto de Nueva Planta debido a que esta isla pertenecía a los británicos oficialmente desde el Tratado de Utrecht. Durante este siglo XVIII se van produciendo diferentes dominios de Menorca entre británicos, españoles y franceses, pero las instituciones consiguen mantenerse incluso después de la definitiva toma de la isla por parte de España el 1802. El modelo administrativo del Antiguo Régimen que prevalecía en Menorca no será eliminado hasta que la Constitución liberal de 1837 unifique la Administración de todas las provincias españolas. A pesar de que el Decreto no afecta a Menorca, el autor analiza la situación de esta isla durante todo el siglo XviII y el inicio del XIX, algo que no se suele hacer en profundidad en los trabajos que tratan el Decreto de Nueva Planta para Mallorca y que resulta interesante para comprender mejor el contexto en el que se desarrolla.

El volumen se cierra con un apéndice documental, que incluye la trascripción del Decreto de Nueva Planta del 28 de noviembre de 1715 y la Real Cédula del 16 de marzo de 1716 con la que se promulga este Decreto.

En definitiva, este libro constituye una útil introducción al problema de la Nueva Planta borbónica de Mallorca y cumple así el objetivo esencial planteado por el autor. Debe tenerse en cuenta que el tema generó en el pasado numerosas publicaciones especializadas (M.J. Deyá, J. Juan, A. Planas, A. Santamaría, el propio E. Pascual, entre otros), que analizan aspectos concretos del tema: desde la aplicación del Decreto hasta las diferentes instituciones y cargos que se derivaron. El volumen objeto de esta reseña aborda con éxito la 
función de proporcionar al lector medio un conocimiento general del tema mediante un texto de síntesis divulgativa que, como es habitual en este tipo de obras, no incorpora notas a pie de página, pero sí una bibliografía básica de referencia.

Jaime Miguel Azor Cerdá Universitat de les Illes Balears 